\title{
Asset Price Bubbles with Low Interest Rates: Not All Bubbles are Likely to Emerge*
}

\author{
Jacopo Bonchi ${ }^{\dagger} \quad$ Francesco Simone Lucidi ${ }^{\ddagger}$
}

7th December 2020

\begin{abstract}
Leveraged asset price bubbles, i.e., boom-bust phases in asset prices accompanied by credit overhangs, are more harmful than unleveraged ones, in terms of financial and macroeconomic stability. If bubbles are not all alike, neither are all bubbles likely? As bubbles are difficult to detect in real-time data, early researches focused on the macroeconomic conditions exacerbating the bubbles' nature. We specifically look at a condition that could become more persistent in the aftermath of Covid-19 pandemic: low risk-free interest rates. In an OLG model, we show that the existence condition for a leveraged bubble is more easily met than that of an unleveraged bubble with low interest rates, and thus leveraged bubbly episodes are relatively more likely to emerge than unleveraged ones. Then, we show that this result holds empirically for post-World War II bubbles in advanced economies.
\end{abstract}

JEL Classification Numbers: E43, E44

Keywords: Low interest rates, Leveraged bubbles, Unleveraged bubbles

\footnotetext{
${ }^{*}$ We are grateful to Pierpaolo Benigno, Paolo D'Imperio, Luca Fornaro, Luca Fosso, Maurizio Mostacci, Andrea Polo, Karsten Staehr, Guido Traficante and Lenno Uuskula for their helpful comments.

${ }^{\dagger}$ LUISS Guido Carli. Address: Department of Economics and Finance and School of European Political Economy, Viale di Villa Emiliani 14, 00197, Rome, Italy. Email: jbonchi@luiss .it

$\ddagger$ Sapienza University of Rome. Address: Department of Economics and Law, Via del Castro Laurenziano 9, 00185, Rome, Italy. Email: francescos.lucidi@uniroma1.it
} 
"However, not all asset price bubbles are alike...In particular, some asset price bubbles can have more significant economic effects, and thus raise additional concerns for economic policymakers, by contributing to financial instability"

-Frederic Mishkin, Financial Stability Review no.12 2008, Banque de France

\section{Introduction}

The detrimental economic consequences of the Covid-19 pandemic, along with the policy response of the central banks, could make low risk-free interest rates, if possible, even more persistent. Against this backdrop, asset price bubbles could emerge. If bubbles are not all alike in terms of financial instability, as argued by Mishkin, neither are they all equally likely to emerge with low interest rates? And, in case, what are the peculiar traits of this environment that make a bubble type more likely? Our paper answers these questions by investigating the theoretical and empirical implications of low interest rates for the formation of different types of asset price bubbles.

Low risk-free interest rates are the hallmark of the post-2007 crisis era in many advanced economies. The downward trend of risk-free nominal and real interest rates, started long before the Great Recession, is widely interpreted as a decline in the "natural" interest rate consistent with the potential output and stable prices (Rachel and Smith, 2015, Laubach and Williams, 2016; Holston et al. 2017). Empirical evidence finds that pandemic shocks negatively affect the natural interest rate, envisaging low interest rates (LIR, henceforth) as a likely scenario also for the years after the Covid-19 pandemic (Jordà et al. 2020). The recent review in the FED's monetary policy framework, which is now a "flexible average inflation targeting", reinforces this argument because, by allowing inflation to be above $2 \%$, it opens the door to a low policy rate even with inflation back to the target 1

LIR expose the economy to several forms of financial instability. Risk-taking behaviors and borrowing are encouraged because only risky investments are profitable and credit is cheap, fostering leveraged booms (Dell'Ariccia et al. 2014). Moreover, if the real interest rate falls below the economy's growth rate, asset price bubbles can emerge rationally (Baldwin and Teulings, 2014). In the current pandemic scenario, the rebound in financial markets points to the renewed risk of a bubble in asset prices. Caballero and Simsek (2020b) interpret the recent disconnect between the real and financial sector as consistent with an optimal monetary policy. However, several FED's officials have recently warned of the risk of boom-bust cycles in asset prices underlying LIR (see, e.g., Brainard (2020)).

\footnotetext{
1 "Our evolving understanding of four key economic developments motivated our review...Second, the general level of interest rates has fallen both here in the United States and around the world. Estimates of the neutral federal funds rate, which is the rate consistent with the economy operating at full strength and with stable inflation, have fallen substantially, in large part reflecting a fall in the equilibrium real interest rate, or " $r$-star'" (p.4, Powell 2020.
} 
The burst of speculative bubbles is commonly viewed as an important source of macroeconomic and financial instability, but asset price bubbles are not inherently harmful. If they serve as a store of value without fostering credit growth, namely in the form of unleveraged bubbles, the economic cost of the bubble bursting is limited, and it does not necessarily turn into a financial crisis. Leveraged bubbles, in contrast, are accompanied by credit booms that can painfully hurt the economy, as they are more likely to trigger a financial crisis (Jordà et al., 2015b). The distinction between leveraged and unleveraged bubbles is crucial for studying the potential threats that they pose to financial stability, and thus for understanding if the LIR environment is more prone to the least or most detrimental bubble.

To investigate how LIR foster these two types of bubbles, we first develop a theoretical model that studies the conditions under which they emerge. Then, we test these conditions empirically by exploiting a long historical dataset where leveraged and unleveraged bubbles are identified for several countries.

Our theoretical framework is a stylized two-period overlapping generations (OLG) model that allows for a tractable analysis of LIR and rational bubbles. We augment the model with income inequality, downward nominal wage rigidity, non-neutral monetary policy, and a defaultable debt contract. Income inequality shapes the characteristics of young households in a credit market, where low-income households are borrowers and high-income ones are lenders, and it causes a negative natural interest rate 2 Then, the economy gets stuck in an "LIR" equilibrium with binding zero lower bound (ZLB) on the policy rate and negative real interest rate, as well as inflation below the target and output below the potential because of downwardly rigid wages. In this economic environment, rational and optimizing agents can value a worthless asset, the "bubble", which is risky because its price can collapse to zero with a fixed probability. The bubble is fully unleveraged when lenders are its only owners, while it is fully leveraged when purchased exclusively by borrowers through debt that is defaultable and backed by the bubble itself.

A leveraged bubble emerges if the real interest rate is lower than the economy's growth rate, a condition that is always met in an LIR equilibrium featuring a negative real interest rate, for a positive growth rate. In contrast, a tighter condition on the real interest rate has to be satisfied for the unleveraged bubble to emerge, and thus a negative real interest rate does not guarantee per se its emergence. Intuitively, LIR make risk-free assets not profitable because of a low (negative) return, and thus investors could demand risky bubbly assets, which guarantee a higher return, even if their price climbs above the fundamental value. When the bubbly investment is unleveraged, investors/lenders invest their own resources and take into account the probability of the bubble bursting, so that the risk-adjusted return on the bubble can be lower than the real interest rate. In the case of a leveraged bubble, instead, investors/borrowers do not internalize the bubble-bursting risk because they shift this risk to lenders by collateralizing bubbly

\footnotetext{
${ }^{2}$ Income inequality is intended to capture a wide array of forces putting downward pressure on the natural interest rate (see, e.g., Summers, 2014 Eggertsson et al. 2019], among others, the pandemic shock studied in Jordà et al. (2020). At the same time, this assumption replicates the increase in top income shares that has been channeled into borrowing by the bottom $90 \%$ of the income distribution (Mian et al. 2020a b), allowing us to account for asset bubbles held by different types of investors for different motives.
} 
assets, and defaulting on their obligations if the bubble bursts. As a consequence, borrowers find the bubbly investment more profitable relative to risk-free assets because it guarantees a higher return in the case the bubble survives.

We interpret this result as a higher probability to observe a leveraged bubble than an unleveraged one with LIR, and we provide this theoretical finding with an empirical analysis on a panel of 17 countries in the 1945-2016 period, by using the macrohistory database by Jordà et al. (2015a). In particular, we first identify asset bubbles by looking at the deviations from the long-run trend of both stock and house prices. Then, we differentiate leveraged from unleveraged bubbles by identifying those bubbly episodes occurring with credit booms. The empirical model features a logistic estimation, where the dependent variable measures the probability of a leveraged vs an unleveraged bubble, distinguishing the periods that anticipate the emergence of the two types of bubbles. The estimations point to a higher probability of a leveraged bubble compared to an unleveraged one the lower is the real interest with respect to the economy's growth rate. Provided the latter condition, we find slight evidence that leveraged bubbles are more likely in the case of a negative real interest rate. However, since negative real rates are rarely concomitant with bubbly periods in historical data, we take this result with a grain of salt. The results are robust to different specifications of the empirical model, different definitions of the real interest rate, and to the use of different sub-samples of our dataset.

The remainder of the paper is organized as follows. Section 2 summarizes the related literature to both the theoretical and the empirical parts. We present the theoretical model in Section 3 , whereas we study the existence conditions for leveraged and unleveraged bubbles under LIR in Section 4 . Section 5 illustrates the empirical model and the main results. Section 6 presents concluding remarks.

\section{Related literature}

The theoretical part of this paper is related to two strands of the literature. First, it is inspired by the recent literature on "secular stagnation" that views LIR as a result of the historical decline in the natural interest rate (e.g., Baldwin and Teulings, 2014, Summers, 2014, Gordon, 2015). We characterize the bubble type that is likeliest to emerge in such an economic environment. Specifically, we exploit the OLG model of "secular stagnation" in Eggertsson et al. (2019), properly augmented with an incomplete credit market and rational bubbles, to study the conditions under which leveraged and unleveraged bubbles arise. Our extended model also features income inequality and binding borrowing constraints, generating different propensities to save among young households, and thus an "indebted demand" as in Mian et al. (2020a). Unlike the latter, in our framework the increase in indebted demand is not the result of an exogenous expansion in the borrowing capacity, but the consequence of a leveraged bubble arising endogenously with LIR.

Second, the theoretical part relates to the extended theoretical literature on asset price 
bubbles. We adopt the OLG approach to study rational bubbles. As is standard in this approach, we assume the source of the bubble is an excess of saving over investment, and the bubble can be both a store of value (Samuelson, 1958, Tirole, 1985) and a collateral (Martin and Ventura 2011). On the one hand, we enrich the standard OLG model of rational bubbles with a non-neutral monetary policy and a negative natural interest rate. A negative natural rate that makes the ZLB binding distinguishes our work from that of Gali (2014) and Asriyan et al. (2019), who study the effect of monetary policies during bubbly episodes, not the conditions for the emergence of different bubbles during ZLB episodes. On the other hand, we model leveraged and unleveraged bubbles along the lines of Bengui and Phan (2018), who introduce risk-shifting in a framework with rational bubbles and full information. Bengui and Phan (2018) limit their analysis of the existence conditions for the two types of bubbles to an endowment economy. We extend their results to a production economy in which the interaction of a negative natural interest rate and the ZLB causes LIR. Moreover, we overturn their approach to leveraged and unleveraged bubbles: while they look at the role of the credit market structure in determining the bubble's nature, given the real interest rate, we look at the role of the real interest rate in determining the bubble's nature, given the credit market structure.

The empirical part of the paper relates to the empirical works about credit booms identification such as Mendoza and Terrones (2012, 2008). We borrow from the latter the idea of identifying credit overhangs as "unusual" expansions in the cyclical component of private credit, where unusual is qualified by looking at its standard deviation. As put forward in Jordà et al. (2013) and Jordà et al. (2015a b), credit booms are a source of financial crises. In general, these authors employ a wide historical dataset and test whether credit (asset price) booms predict financial crises through a logistic early warning model. Along with Alessi and Detken (2018), their empirical framework provides evidence that credit-driven asset price bubbles exacerbate both the risks of financial crises and subsequent output losses. With respect to the latter, this paper takes a different perspective. Rather than financial crises, bubble events are the object of our analysis, and we use the real interest rate and other macro controls as predictors. Moreover, as for the theoretical model, our empirical analysis is agnostic about the prediction and consequences of the bubble bursting. In fact, we share the same motivation as Jordà et al. (2015b) with an opposite viewpoint. While they focus on the relationship between leveraged and unleveraged bubbles with financial crises, we focus on the conditions determining the two types of bubbles. For this reason, we do not study the magnitude and the duration of the bubbles, as Jordà et al. (2015b) do instead.

Finally, the paper relates to the vast empirical literature that studies the real interest rates in the context of relatively stable inflation, that is, the natural rate of interest. Earlier literature focused on the role of money in determining the natural rate (Andrés et al. 2009). By following a longer-run perspective, Laubach and Williams (2016), in a Kalman-filter fashion, as in Laubach and Williams (2003), estimate a declining natural rate for many advanced economies. Different approaches with similar results can be found in Hamilton et al. (2016), Borio et al. (2017), 
Lunsford and West (2019), to name a few. All these works focus on the determinants of the natural real rate and provide model-based estimations. Consistently with our theoretical part, we take an "ex-ante" Fisher-equation real rate instead and study its implications for financial stability in a LIR environment.

\section{Theoretical model}

We study a two-period OLG economy in which agents form expectations rationally and are perfectly informed. The size of the generations is constant and normalized to one, and the supply-side of the model is standard. We extend this framework in three crucial dimensions.

Income inequality. A share $\chi$ of the young households are lenders because they earn a sufficiently high income to save, while the remaining share consists of borrowers who desire to borrow because of a low income. Throughout the paper, the superscript $L$ denotes lenders, and the superscript $B$ denotes borrowers.

Markets for assets. There exists an incomplete credit market in which young borrowers sell a one-period bond to young lenders. As borrowers cannot commit to paying all their outstanding debt, they issue a non-contingent standard debt contract, which is defaultable, and whose gross real interest rate charged, $\left(1+r_{t}\right)$, does not depend on the size of the loan (Allen and Gale, 2000, Ikeda and Phan, 2016). In case of default, lenders can repossess only a fraction of the original claims in the form of "fundamental" and "bubbly" collaterals ${ }^{3}$

Yet, old households own a worthless asset (bubble) in fixed unit supply, which is sold at a positive price to young households, if the latter expect to re-sell it at a higher price. Trading happens after learning if the bubble's price is positive or zero. As initiating the bubble is costless for old households, the bubble's price cannot be negative. However, if investors no longer believe in the future appreciation of the bubble due to, for example, a negative sentiment shock, the bubble bursts and its price collapses to zero. Each period the price of the bubble $\tilde{p}_{t}^{b}$ can go to 0 with probability $\rho \in[0,1)$, and the bubble never re-emerges after crashing (Weil, 1987). Conditional on not being collapsed, the price of the bubble is $\tilde{p}_{t}^{b}=p_{t}^{b}>0$.

Downward nominal wage rigidity and non-neutral monetary policy. Nominal wages cannot grow less than a fraction $\gamma$ of the intended inflation target $\Pi^{*}$, and the downward nominal wage rigidity (DNWR) makes monetary policy non-neutral $!^{4}$ The central bank sets the nominal

\footnotetext{
${ }^{3}$ The assumption of debt-inelastic interest rate allows for risk-shifting in equilibrium because the real interest rate does not increase if borrowers take on more debt via the bubbly collateral. This simplifying assumption replicates the main feature of a more complicated setting with "credit pooling" (e.g., Bengui and Phan 2018), in which loans of different borrowers are pooled together, along with their individual default risks, fostering riskshifting from borrowers to lenders. If we assume the real interest rate increases with debt, and thus lenders price the default risk of borrowers, a leveraged bubble still exists in the case of bubble's full collateralization considered, as shown in Bengui and Phan (2018).

${ }^{4}$ If we alternatively assume Calvo pricing Calvo 1983, the model would be unchanged, as shown in Eggertsson et al. (2019). However, the DNWR allows replicating ZLB episodes associated with output losses, as in the LIR environment emerged from the outbreak of the Covid-19 pandemic. Furthermore, indexing the minimum wage growth rate to the inflation target delivers a positive, below the target inflation rate that is consistent with the recent evidence of the advanced economies.
} 
interest rate $i_{t}$, which is constrained by the ZLB, according to a standard Taylor rule.

In this section, we outline the salient features of our model: the borrowers' and lenders' maximization problem and the asset markets. We postpone the explanation of the remaining elements to the next section 5

\subsection{Borrowers and lenders}

Households have logarithmic preferences and their consumption in the two stages of life is $C_{y, t}^{i}$ and $C_{o, t+1}^{i}$, where $i \in\{B, L\}$. When they are young, agents supply inelastically their own labor endowment and run firms. Firms are identical, and thus real profits $\frac{Z_{t}}{P_{t}}$ are the same regardless of the firm's owner. Moreover, all workers earn the same real wage $\frac{W_{t}}{P_{t}}$, where $W_{t}$ is the nominal wage and $P_{t}$ is the average price level. However, labor endowment is not equally distributed among households, and the households with higher endowment supply more labor and work more, earning a higher total income. Young lenders have a high labor endowment and a high total income, $Y_{t}^{L}$, to save for retirement. By contrast, young borrowers have a low labor endowment. Hence, they borrow to make up for a low total income $Y_{t}^{B}$, and pay a lump-sum $\operatorname{tax} T$ to finance social security benefits in old age. The borrowers' problem is

$$
\max _{d_{t}^{B} \geq 0, b_{t}^{B} \geq 0} E_{t}\left(\ln C_{y, t}^{B}+\beta \ln C_{o, t+1}^{B}\right)
$$

s.t.

$$
\begin{gathered}
C_{y, t}^{B}=Y_{t}^{B}+d_{t}^{B}-\tilde{p}_{t}^{b} b_{t}^{B}-T \\
C_{o, t+1}^{B}=T+\tilde{p}_{t+1}^{b} b_{t}^{B}-\left(1-\xi_{t+1}\right)\left(1+r_{t}\right) d_{t}^{B}-\xi_{t+1}\left(D+\phi \tilde{p}_{t+1}^{b} b_{t}^{B}\right) \\
\left(1+r_{t}\right) d_{t}^{B} \leq D+\phi p_{t+1}^{b} b_{t}^{B} .
\end{gathered}
$$

$\beta$ is the subjective discount factor, and $Y_{t}^{B}=\frac{Z_{t}}{P_{t}}+\frac{W_{t}}{P_{t}} L_{t}^{B}$, where the demand for borrowers' labor services $L_{t}^{B}$ can be lower or equal to their supply/endowment $\bar{L}^{B}$.

We assume borrowers are credit constrained 6

$$
d_{t}^{B}=\frac{D+\phi p_{t+1}^{b} b_{t}^{B}}{1+r_{t}}
$$

\footnotetext{
${ }^{5}$ We refer to Appendix A.1 for a thorough explanation of the supply-side, the DNWR and monetary policy. In Appendix A.1 we also explain in detail the source of income inequality.

${ }^{6}$ We impose

$$
D<\frac{T}{1+\beta}-\frac{\beta}{1+\beta}\left(1+r_{t}\right)\left(Y_{t}^{B}-T\right)
$$

and

$$
D<\frac{T}{[1+\beta(1-\rho)]}-\frac{\beta(1-\rho)}{1+\beta(1-\rho)}\left[\left(1+r_{t}\right)\left(Y_{t}^{B}-T-p_{t}^{b} b_{t}^{B}\right)+p_{t+1}^{b} b_{t}^{B}\right] .
$$

As borrowers cannot smooth consumption both in a bubbleless economy and in a bubbly one with full collateralization of the bubble $(\phi=1)$ because of these parametric assumptions, they have no incentive to also save and lend. In the event of default, lenders repossess effectively the maximum possible amount only if the bubble survives, $\tilde{p}_{t+1}^{b}=p_{t+1}^{b}>0$. Indeed, we could alternatively express the borrowing constraint as $\left(1+r_{t}\right) d_{t}^{B}=D+\phi \max \left\{\tilde{p}_{t+1}^{b}\right\} b_{t}^{B}$.
} 
Their level of borrowing $d_{t}^{B}$ is limited to the present value of the maximum amount that lenders can repossess in the case of default, namely a "fundamental" collateral, $D \in(0, T)$, and a fraction $\phi \in[0,1]$ of the borrowers' bubble holdings $b_{t}^{B}$, which constitutes the "bubbly" collateral (Bengui and Phan, 2018). As a consequence, the bubbly asset has a twofold role for borrowers: a collateral, which allows to collect additional resources, $\phi p_{t+1}^{b} b_{t}^{B}$, to consume today, and a store of value, which allows to carry over resources, $\tilde{p}_{t+1}^{b} b_{t}^{B}$, to consume tomorrow. Borrowers choose the optimal amount of bubble holdings $b_{t}^{B}$, which can be positive or zero, anticipating their default decision when old. The default decision at time $t+1$ is governed by the rule:

$$
\xi_{t+1}=\left\{\begin{array}{lll}
0 & \text { if } & \left(1+r_{t}\right) d_{t}^{B} \leq D+\phi \tilde{p}_{t+1}^{b} b_{t}^{B} \\
1 & \text { if } & \left(1+r_{t}\right) d_{t}^{B}>D+\phi \tilde{p}_{t+1}^{b} b_{t}^{B} .
\end{array}\right.
$$

If repaying is at least as convenient as defaulting and giving up fundamental and bubbly collaterals, borrowers repay all their outstanding debt, $\left(1+r_{t}\right) d_{t}^{B}$, and $\xi_{t+1}$ is zero. On the contrary, borrowers go bankrupt when defaulting is the most convenient option, and $\xi_{t+1}$ equals one. The rule (2) combined with the borrowing limit (1) implies that borrowers default only if the bubble bursts, namely for $\tilde{p}_{t+1}^{b}=0$.

The lenders' maximization problem is

$$
\max _{d_{t}^{L} \geq 0, b_{t}^{L} \geq 0} E_{t}\left(\ln C_{y, t}^{L}+\beta \ln C_{o, t+1}^{L}\right)
$$

s.t.

$$
\begin{gathered}
C_{y, t}^{L}=Y_{t}^{L}-d_{t}^{L}-\tilde{p}_{t}^{b} b_{t}^{L} \\
C_{o, t+1}^{L}=\tilde{p}_{t+1}^{b} b_{t}^{L}+\left(1-h_{t+1}\right)\left(1+r_{t}\right) d_{t}^{L} .
\end{gathered}
$$

Although also the demand for the lenders' labor services $L_{t}^{L}$ can be lower than the supply/endowment $\bar{L}^{L}$, lenders get a sufficiently high income, $Y_{t}^{L}=\frac{Z_{t}}{P_{t}}+\frac{W_{t}}{P_{t}} L_{t}^{L}$, to save, and they choose either the optimal bond and bubble purchases, $d_{t}^{L}$ and $b_{t}^{L}$. However, as lenders do not take on debt 7 they can use the bubbly asset exclusively as a store of value. Moreover, they can repossess a share of their original claims in the event of borrowers' default, and the remaining fraction of losses on loans is the haircut $h_{t+1}$, which can take the following values:

$$
h_{t+1}=\left\{\begin{array}{llll}
0 & \text { if } & \xi_{t+1}=0 \\
1-\frac{(1-\chi)}{\chi} \frac{D}{\left(1+r_{t}\right) d_{t}^{L}} & \text { if } & \xi_{t+1}=1 .
\end{array}\right.
$$

In the absence of default $\left(\xi_{t+1}=0\right)$ the haircut is zero. Instead, if borrowers pledge bubbly assets and then default because of the bubble bursting $\left(\xi_{t+1}=1\right)$, lenders can recover only the aggregate fundamental collateral $(1-\chi) D$, which is a fraction of the original total claims $\chi\left(1+r_{t}\right) d_{t}^{L}$.

\footnotetext{
${ }^{7}$ In principle, high-income households could also borrow and default, but if a fraction of their savings can be seized the optimal borrowing is zero (Bengui and Phan, 2018).
} 
We solve the two households' maximization problem in Section 4, where we study a bubbleless economy and a bubbly one separately. However, the takeaway here is that lenders and borrowers have a different motive to hold the bubble. Lenders need an alternative store of value when investment opportunities are few, while borrowers hold bubbly assets mainly because of their collateral value, which depends on their degree of pledgeability $\phi$, namely the percentage of the bubble's value that turns into credit. When bubbles are highly pledgeable, a high percentage of their value becomes credit, and borrowers buy them to collect extra resources. As bubbles foster credit in this case, they are leveraged if borrowers (partially or fully) hold them, and they are (fully) unleveraged if only lenders buy the bubbly assets.

\section{Equilibrium}

Competitive equilibrium: Given $W_{-1}, d_{-1}^{L}$ and $p_{0}^{b} \geq 0$, a competitive equilibrium consists of the prices $\left\{P_{t}, W_{t}, r_{t}, i_{t}, p_{t}^{b}\right\}$, the quantities $\left\{d_{t}^{L}, b_{t}^{L}, d_{t}^{B}, b_{t}^{B}, C_{y, t}^{L}, C_{o, t}^{L}, C_{y, t}^{B}, C_{o, t}^{B}, Y_{t}, Z_{t}, L_{t}, L_{t}^{L}, L_{t}^{B}\right\}$, the haircut $h_{t+1}$ and the default decision $\xi_{t+1}$ such that:

- households maximize their lifetime utility and firms maximize their profit;

- $Y_{t}=(1-\chi)\left(C_{y, t}^{B}+C_{o, t}^{B}\right)+\chi\left(C_{y, t}^{L}+C_{o, t}^{L}\right)($ goods market clears $)$;

- $L_{t}=\bar{L}$ for $W_{t}=W_{t}^{\text {flex }}$ or $L_{t}<\bar{L}$ for $W_{t}=\gamma \Pi^{*} W_{t-1}$ (labor market clears or labor rationing);

- $(1-\chi) d_{t}^{B}=\chi d_{t}^{L}$ and $(1-\chi) b_{t}^{B}+\chi b_{t}^{L}=(1-\chi) b_{t-1}^{B}+\chi b_{t-1}^{L}=1$ if $\tilde{p}_{t}^{b}=p_{t}^{b}>0$

(markets for assets clear);

- monetary policy follows a Taylor rule, the Fisher equation holds, $h_{t+1}$ satisfies (3).

The competitive equilibrium is bubbleless for $p_{0}^{b}=0$, while it is bubbly for $p_{0}^{b}>0$. Here, we focus on bubbleless and bubbly steady state equilibria in which the variables take a constant value. We remove the time subscript accordingly. We also characterize the behavior of the labor market, which incorporates the labor rationing approach as in Schmitt-Grohé and Uribe (2016). Indeed, given the DNWR, the demand for the borrowers' and lenders' labor services can equal or not the corresponding supply, and thus the aggregate labor demand, $L_{t}=(1-\chi) L_{t}^{B}+\chi L_{t}^{L}$, can fall short of the aggregate supply, $\bar{L}=(1-\chi) \bar{L}^{B}+\chi \bar{L}^{L}$, due to rationing 8

\footnotetext{
${ }^{8}$ Any fall in the aggregate labor demand relative to the economy's labor supply/endowment causes a proportional decline in the demand for borrowers' and lenders' labor services, without redistributing income among young households. This result derives from the assumption that the demand for borrowers' and lenders' labor services is a constant share of the aggregate labor demand, and it equals the corresponding share of the aggregate labor supply/endowment. We formally show this point in Appendix A.1.2
} 


\subsection{Bubbleless economy}

We first study a bubbleless steady state that features binding ZLB and replicates the current LIR environment characterizing most of the advanced economies. Before analyzing this steady state equilibrium of the economy, we define the natural interest rate because it plays a crucial role in determining the general equilibrium. The credit market clearing condition is

$$
(1-\chi) d^{B}=\chi d^{L}
$$

and the market for credit clears at the real interest rate

$$
\left(1+r_{n b}\right)=\frac{(1-\chi)}{\chi} \frac{(1+\beta)}{\beta} \frac{D}{Y^{L}},
$$

where the subscript $n b$ denotes a "no-bubble" economy. The equilibrium real interest rate equates the aggregate demand for credit and the aggregate supply of saving in equation (4) 9 and it coincides with the natural rate of interest $1+r_{n b}^{f}$ at the potential level of production $Y=Y^{f}$, whose share attributed to lenders is $\chi Y^{f, L}$. Equation (5) shows that a large share of the total income for lenders, $\chi Y^{L}$, results in a negative real interest rate, $1+r_{n b}<1$, and thus in a negative natural rate of interest ${ }^{10}$

We can express the steady state equilibrium through aggregate supply and demand, which are both characterized by two regimes. The regime of supply depends on the DNWR through the inflation rate $\Pi$. For $\Pi \geq \gamma \Pi^{*}$, the DNWR does not bind and the aggregate supply (AS) coincides with the potential output, $Y_{A S}=Y^{f}$. In this case, labor market clearing requires that $W$ increases at least as the minimum wage growth imposed by the DNWR. Hence, the nominal wage can equal its flexible level corresponding to full employment $\left(W=W^{\text {flex }}\right)$, the labor market clears $(L=\bar{L})$, and the economy runs at the potential level. On the contrary, if an increase in $W$ of less than $\gamma \Pi^{*}$ is necessary to clear the labor market, the DNWR binds, and thus wage/price inflation is given by $\Pi=\gamma \Pi^{*}$ for any $L \leq \bar{L}$. In the case of binding DNWR, labor rationing occurs so that involuntary unemployment arises. Furthermore, the level of output and employment is demand-determined. We depict the AS curve as a solid red line in Figure 1 , where the first regime corresponds to the vertical segment and the second one to the horizontal segment.

The regime of the aggregate demand (AD) depends on whether or not the ZLB binds. To save space, we put the equations defining the two regimes of the $\mathrm{AD}$ in Appendix $\mathrm{A} .3$ and we describe here their economic meaning. Far away from the ZLB, there exists a negative relationship between inflation and output, which corresponds to the downward-sloping segment of the AD

\footnotetext{
${ }^{9}$ For $p^{b}=0$ and $h=0$ in a bubbleless economy, the individual demand for credit is $d^{B}=D /(1+r)$, while the credit supply from each lender is a constant share $\beta /(1+\beta)$ of his/her total income $Y^{L}$, given logarithmic preferences.

${ }^{10}$ Although the income of lenders is endogenously determined by output, $\chi Y^{L}$ is a constant share of $Y$, independently of output, because of the assumption that the demand for the lenders' and borrowers' labor services is a constant share of the aggregate labor demand. See Appendix A.1.2 for more details.
} 
Figure 1: LIR Equilibrium in a Bubbleless Economy

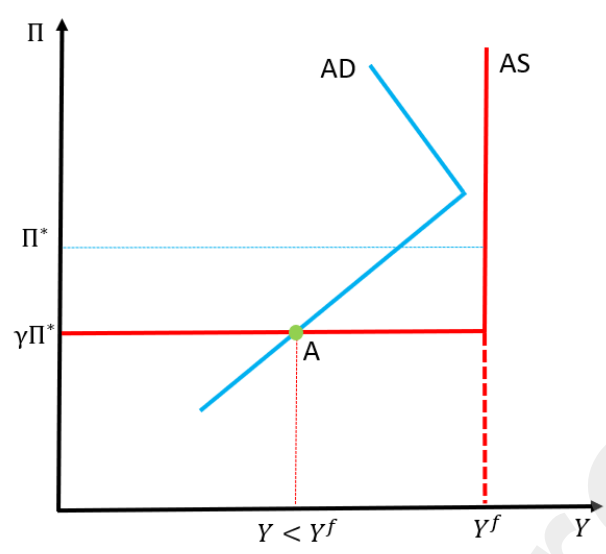

curve depicted in blue in Figure 1. This relationship turns positive at the ZLB, as shown by the upward-sloping segment of the AD curve in the same figure. If the ZLB is not binding, the central bank reacts to higher inflation by raising the policy rate more than proportionally, contracting so demand and stabilizing inflation around the target. Instead, if the ZLB binds, the inflation rate determines the real interest rate through the Fisher equation, and when inflation rises, the real rate falls and the demand increases.

The crossing between the AS and the AD curves identifies the steady state equilibrium, and the relationship between $1+r_{n b}^{f}$ and $\Pi^{*}$ determines its nature because it governs the regime of monetary policy. When $1+r_{n b}^{f}<1$ due to excessive income inequality and, specifically,

$$
1+r_{n b}^{f}<\frac{1}{\Pi^{*}}<1
$$

the ZLB constrains the monetary policy. The positive inflation target $\left(\Pi^{*}>1\right)$, is not high enough to drive the real interest rate to its negative natural level through standard monetary policy tools. Therefore, the central bank cannot set a positive policy rate, and a binding ZLB implies low nominal and real risk-free interest rates. The equilibrium described corresponds to point A in Figure 1. The LIR equilibrium features binding ZLB and a negative real interest rate, as well as inflation that is positive but below the target and output that is below the potential 
because the DNWR is at work:11|2

$$
\begin{gathered}
i=0 \\
1+r_{n b}^{f}<1+r_{n b}<1 \\
1<\Pi=\gamma \Pi^{*}<\Pi^{*} . \\
Y<Y^{f}
\end{gathered}
$$

\subsection{Bubbly economy}

Now, we investigate how unleveraged and leveraged bubbly equilibria arise starting from the bubbleless equilibrium with LIR. As "mixed" bubbles are fairly infrequent in data, we restrict our analysis to the cases of the fully unleveraged bubble, in which only lenders hold the bubbly assets, and the fully leveraged bubble, in which borrowers purchase the entire supply of bubbles. Specifically, we solve the lenders' and borrowers' maximization problem in an unleveraged and in a leveraged bubbly equilibrium, to identify the conditions under which the two bubble types emerge.

\subsubsection{Unleveraged bubble}

A fully unleveraged bubble can arise for $\phi=0$. As borrowers cannot collateralize the bubbly assets, they have a weak incentive to hold them, and we assume accordingly only lenders invest in the bubble, $b^{B}=0$ and $b^{L}=1 / \chi$, to simplify the analysis ${ }^{13}$ In this case, there is no default risk, $\xi=h=0$, and the individual demand for credit is

$$
d^{B}=\frac{D}{1+r}
$$

For the lenders' problem, the budget constraints become

$$
C_{y}^{L}=Y^{L}-d^{L}-p^{b} b^{L}
$$

\footnotetext{
${ }^{11}$ We report all the remaining variables in Appendix A.4 The shape of the DNWR does not affect the nature of the LIR equilibrium (see, e.g., Ascari and Bonchi 2019 Eggertsson et al. 2019), which is determinate, as in Eggertsson et al. (2019), because the assumption of debt-constrained households rules out an aggregate Euler equation similar to that in representative agent models. A formal derivation of the condition for determinacy is available upon request.

${ }^{12}$ For $1+r_{n b}^{f}<1$, condition $\sqrt{6}$ guarantees the unique equilibrium is the LIR one just outlined. However, if 6 does not hold and $\Pi^{*}>1 / \gamma\left(1+r^{f}\right)$, the unique equilibrium is different from that one because it does not feature a binding ZLB, despite a negative natural (=real) interest rate (Ascari and Bonchi 2019). Our theoretical findings hold also considering this alternative equilibrium, given that a negative real interest rate is crucial for our results, not a binding ZLB. Notwithstanding, the alternative equilibrium features inflation at the target that is inconsistent with the current evidence of the advanced economies, likewise a positive policy rate.

${ }^{13}$ As the bubble is a complex security that is both store of value and collateral for borrowers, they could hold bubbly assets even if $\phi=0$. We prove this result formally in Appendix A.5 However, $b^{B}>0$ does not alter the nature of the bubbly equilibrium, which is fully unleveraged by construction because there is no bubble's collateralization.
} 


$$
C_{o}^{L}=\left\{\begin{array}{lll}
(1+r) d^{L} & \text { bubble } & \text { bursting } \\
p^{b} b^{L}+(1+r) d^{L} & \text { bubble } & \text { survival }
\end{array}\right.
$$

while the resulting optimality conditions expressing the choice of bubbly assets and lending are

$$
\begin{gathered}
\frac{1}{C_{y}^{L}} p^{b}=\beta(1-\rho)\left[\frac{1}{p^{b} b^{L}+(1+r) d^{L}}\right] p^{b} \\
\frac{1}{C_{y}^{L}}=\beta(1+r)\left[\rho \frac{1}{(1+r) d^{L}}+(1-\rho) \frac{1}{p^{b} b^{L}+(1+r) d^{L}}\right] .
\end{gathered}
$$

The general interpretation of these two equations is straightforward and not particularly relevant. Instead, what is relevant for the existence of an unleveraged bubble is the fact that lenders bear the risk of bursting completely. The return on the bubble, on the right-hand side of equation (8), is positive only if it survives, an event occurring with probability $1-\rho$, while it is zero in the event of bubble bursting occurring with probability $\rho$. Furthermore, the lenders' consumption level in old age, and thus its marginal utility, varies depending on whether the bubble bursts or not in equation (9), because the bubble bursting reduces the available income of lenders. We get the equilibrium price of the bubble,

$$
p^{b}=(1-\rho) \frac{\beta}{1+\beta} \chi Y^{L}-(1-\chi) D,
$$

from equations $(4),(7),(8)$, and $(9), 14$ Then, we can rearrange the condition for the existence of an unleveraged bubble, $p^{b}>0$, as

$$
1-\rho>1+r_{n b}=\frac{(1-\chi)}{\chi} \frac{(1+\beta) D}{\beta Y^{L}} .
$$

The excess of saving, due to income inequality, drives both the natural and the real interest rate in negative territory, and the economy gets stuck in an LIR equilibrium. As there is no sufficient store of value in the bubbleless economy, lenders will buy intrinsically worthless assets if their return, $1-\rho$, is higher than the bonds' return, $1+r_{n b}$. Therefore, lenders, who invest their own income and bear the bubble-bursting risk, will value the bubble as long as it is not extremely risky, namely if $\rho<-r_{n b}$ for $r_{n b}<0$. Furthermore, LIR foster the unleveraged bubble through a negative real interest rate, $1+r_{n b}<1$, making condition 110 easier to be met. However, a negative real rate is not sufficient per se for the existence of an unleveraged bubble because it does not necessarily make the bubble more profitable than bonds, once considered the bubble bursting risk $\rho$. These results extend to the case of a positive economy's growth rate, $g>0$, whose corresponding condition for the existence of the unleveraged bubble is $(1-\rho)(1+g)>1+r_{n b} t^{15}$

\footnotetext{
${ }^{14}$ Of course, this system of equations provides also the equilibrium values for $d^{B}, d^{L}$ and $(1+r)$, which are not reported because they are not relevant for our result. We solve a similar system of equations with the same unknown variables in the case of a leveraged bubble. Also in that case, we only focus on the value of $p^{B}$.

${ }^{15}$ The economy's growth rate is currently negative in most of the advanced economies. However, our analysis of unleveraged and leveraged bubbles refers to the prospective situation in which $g$ will turn positive, after the
} 
A sufficiently high probability of bubble bursting, $\rho>\frac{g-r_{n b}}{1-g}$, and/or an excessively low economy's growth rate, $g<\frac{r_{n b}+\rho}{1-\rho}$ for $\rho>-r_{n b}$, can prevent the emergence of the bubble also in this case, despite the negative real interest rate. We can summarize these results in the following proposition.

Proposition 1. Assume $\phi=0$, then a fully unleveraged bubble exists only if the gross real interest rate prevailing in a bubbleless economy, $1+r_{n b}$, is lower than the risk-adjusted return from the bubble, $(1-\rho)(1+g)$ for $g \geq 0$. As a consequence, a negative real interest rate, $1+r_{n b}<1$, is not a sufficient condition for the existence of the fully unleveraged bubble.

\subsubsection{Leveraged bubble}

A fully leveraged bubble exists only if $\phi=1$. Borrowers will find bubbles extremely attractive if they can wholly pledge them in the credit market, and their demand fulfills all the supply in this case, $b^{B}=1 /(1-\chi)$ and $b^{L}=0{ }^{16}$ The bubble is then leveraged because it is used as collateral by borrowers ${ }^{17}$ The lenders' budget constraints are different from the unleveraged case because $h \geq 018$ Lenders' optimal condition in equation 80 holds now with inequality, whereas, for $b^{L}=0$, the one in equation $(9)$ reduces to the equation $1 / C_{y}^{L}=\beta / d^{L}$, which can be rearranged to express the credit supply:

$$
d^{L}=\frac{\beta}{1+\beta} Y^{L} .
$$

For borrowers, the constraints of their maximization problem are now

$$
\begin{gathered}
C_{y}^{B}=Y^{B}+d^{B}-p^{b} b^{B}-T \\
C_{o}^{B}=\left\{\begin{array}{lll}
T-D & \text { bubble } & \text { bursting } \\
T+p^{b} b^{B}-(1+r) d^{B} & \text { bubble } & \text { survival. }
\end{array}\right.
\end{gathered}
$$

Borrowers' optimal conditions are then:

$$
\frac{1}{C_{y}^{B}} p^{b}=\beta(1-\rho)\left[\frac{1}{T+p^{b} b^{B}-(1+r) d^{B}}\right] p^{b}+\lambda_{d}^{B} p^{b}
$$

downturn due to the Covid-19 pandemic, but $r$ remains negative because of a negative natural interest rate.

${ }^{16}$ If borrowers hold the bubble for $\phi=1$, lenders optimally choose not to. Formal proof of this is given in Appendix A.6 Intuitively, as $1+r=1$ in a fully leveraged bubbly equilibrium, lenders invest all their savings in bonds, which guarantee a higher return than that of bubbles, $1-\rho$. Bonds are now risky assets, unlike the unleveraged case, because they are backed by borrowers' bubble holdings.

${ }^{17}$ The assumption of $\phi=1$ implies that the higher debt, taken on through the bubbly collateral, exhausts the price of the bubble fully in the next period, even if the bubble survives. Therefore, although the bubble is in principle both a store of value and a collateral for borrowers, it can be effectively used only as collateral, capturing precisely the essence of a purely leveraged bubbly episode.

${ }^{18}$ They are now

$$
\begin{gathered}
C_{y}^{L}=Y^{L}-d^{L}-p^{b} b^{L} \\
C_{o}^{L}=\left\{\begin{array}{cll}
(1-h)(1+r) d^{L} & \text { bubble } & \text { bursting } \\
p^{b} b^{L}+(1+r) d^{L} & \text { bubble } & \text { survival, }
\end{array}\right.
\end{gathered}
$$

where $h=\frac{\phi p^{b} b^{B}}{D+\phi p^{b} b^{B}}=\frac{p^{b} b_{t}^{B}}{D+p^{b} b^{B}}$. 


$$
\lambda_{d}^{B}=\frac{1}{C_{y}^{B}(1+r)}-\beta(1-\rho) \frac{1}{T+p^{b} b^{B}-(1+r) d^{B}}>0,
$$

where $\lambda_{d}^{B}$ is the Lagrange multiplier associated with the credit constraint. The latter is strictly positive because borrowers are credit constrained even if the bubble can be fully collateralized, as implied by (1). Once again, the optimality conditions are not particularly significant. Instead, by plugging (11) into the borrowers' budget constraint in old age (bubble survival case), we notice something more relevant. Borrowers, unlike lenders in the previous case, do not bear the risk of bubble bursting. Indeed, regardless of whether the bubble bursts or not, they always consume $T-D$ in the second period. This peculiar feature of the leveraged bubble crucially affects the condition for its existence, distinguishing it starkly from the unleveraged bubble. We can obtain the equilibrium price of a fully leveraged bubble,

$$
p^{b}=\frac{\beta}{1+\beta} \chi Y^{L}-(1-\chi) D,
$$

through equations (1), (4), 11), 12,, 13$) \cdot p^{b}$ is positive and the bubble exists if

$$
1>1+r_{n b}=\frac{(1-\chi)}{\chi} \frac{(1+\beta) D}{\beta Y^{L}} .
$$

From an economic viewpoint, we can interpret equations (10) and (14) in the same way. Rational bubbles can emerge if the bubbleless economy lacks sufficient investment opportunities so that the supply of savings exceeds the demand for borrowing. However, unlike in equation (10), the probability of bubble bursting $\rho$ does not enter equation (14) because of risk-shifting as in Bengui and Phan (2018). If borrowers pledge bubbly assets to collect additional resources to consume, they choose to default in case of bubble bursting and repay only the fundamental collateral. Hence, by borrowing against the bubble, borrowers shift the downside-risk of the bubbly investment to lenders, and they do not need to internalize the risk of bubble collapse, unlike lenders for the unleveraged bubble. As a consequence, bubbly assets no longer need to have a sufficiently high probability of surviving to be valued, and thus leveraged bubbles are generally riskier than unleveraged ones. Furthermore, not only LIR foster the leveraged bubble, but the negative real interest rate prevailing in an LIR equilibrium is a sufficient condition for its emergence. A negative real rate always makes the bubble profitable for borrowers, who only consider the gains from the bubbly investment, disregarding the bubble-bursting risk $\rho$. These results also apply in the case of a positive economy's growth rate $g>0$, in which the existence of a leveraged bubble requires $1+g>1+r_{n b}$. This discussion leads us to state the following proposition.

Proposition 2. Assume $\phi=1$, then a fully leveraged bubble exists only if the gross real interest rate prevailing in a bubbleless economy, $1+r_{n b}$, is lower than the return from the bubble if it survives, $1+g$ for $g \geq 0$. As a consequence, a negative real interest rate, $1+r_{n b}<1$, is a sufficient condition for the existence of the fully leveraged bubble. 
To summarize, an LIR environment fosters both leveraged and unleveraged bubbles because their existence conditions, $1+r_{n b}<1+g$ and $1+r_{n b}<(1-\rho)(1+g)$, are more easily met. However, the general requirement for the existence of a leveraged bubble is looser than that of an unleveraged one. Furthermore, a negative real rate is a sufficient condition for the existence only of the leveraged bubble if the economy's growth rate is positive, $g>0$. Hence, our theoretical model suggests that, while both bubble types are in absolute more likely to emerge, the leveraged bubble is more likely than the unleveraged one.

\section{Empirical analysis}

The theoretical intuition that leveraged bubbles are more likely to emerge than unleveraged ones with low risk-free interest rates can be formalized as a higher probability of observing a leveraged bubble rather than unleveraged one for $r<g$ (LIR, henceforth) and $r<0$ (NIR, henceforth) hold 19 We test empirically the power of those conditions in discerning leveraged from unleveraged bubbles by employing a long-run macro dataset, the JST Macrohistory Database (Jordà et al. 2013, 2015a b), in a logistic model.

Our analysis covers a sample of annual data for 17 advanced economies from 1945 to 2016 20 Specifically, we use a novel data-release that includes asset price dynamics, and that can be retrieved from Jordà et al. (2019) ${ }^{21}$ We present first the variables involved in the estimation: the real rate of interest, whose historical pattern is compared with that of the economy's growth rate, and the identification of the two bubble types. Then, we illustrate the logistic model and discuss the results.

\subsection{The real interest rate and the economy's growth rate}

The real rate of interest is the core variable of our empirical analysis. We define the risk-free interest rate as a short-term return on safe assets, and we use the 3-months government bond yields as the nominal rate of our benchmark specification. To check the robustness of our results, we also run our empirical model with two other longer-term returns on safe assets, which are less volatile and less influenced by cyclical components ${ }^{22}$

We estimate the "ex-ante" real rate of interest via the Fisher equation: $r_{t}=i_{t}-E_{t} \pi_{t+1}$, where $r_{t}$ and $i_{t}$ are the real and nominal interest rates, and $E_{t} \pi_{t+1}$ is the expected (net) inflation rate. We embrace the standard approach that the real rate should account for time variation

\footnotetext{
${ }^{19}$ Although in the theoretical part we treat LIR and NIR as synonymous, observed data offers a few of NIR periods concomitant with bubbly episodes, hence, we treat NIR as a sub-group of LIR periods.

${ }^{20}$ The countries are Austria, Belgium, Canada, Denmark, Finland, France, Germany, Italy, Japan, the Netherlands, Norway, Portugal, Spain, Sweden, Switzerland, the UK, and the US.

${ }^{21}$ Table 5 of Appendix B summarizes the data used in the empirical analysis.

${ }^{22}$ The different definitions, short-term vs long-term, of the risk-free interest rate are consistent with the different interpretations of the OLG model. On the one hand, we can interpret birth/death as the entry/exit in the credit market (see, e.g., Bernanke and Gertler 1989, Ikeda and Phan, 2016), and thus a period is the length of a loan contract, implying a short-term definition of the risk-free rate. On the other hand, we can interpret a period in the model as the length of a generation, and thus the risk-free interest rate as a long-term rate.
} 
in inflation persistence (Hamilton et al., 2016, Borio et al. 2017; Lunsford and West, 2019). Specifically, we proxy expected inflation by recursively projecting an autoregressive process, $\operatorname{AR}(1)$, estimated over a rolling 10-years window ${ }^{23}$ Then, we subtract expected inflation from the short-term nominal interest rate.

Once the real interest rate $r$ is defined, we can look closely at its relationship with the economy's growth rate $g$ over time. Although the LIR condition, $r<g$, has been used in the empirical literature to detect the presence of dynamic inefficiency, we do not focus on this phenomenon in our data. In fact, the occurrence of LIR periods is not necessarily associated with dynamic inefficiency since we take a risk-free real interest rate, which can be lower than the economy's growth rate also in a dynamically efficient economy (Abel et al., 1989) ${ }^{24}$ Instead, in our view the LIR condition, along with the NIR one, is a potential "early warning" of the coming bubble's nature to be tested empirically.
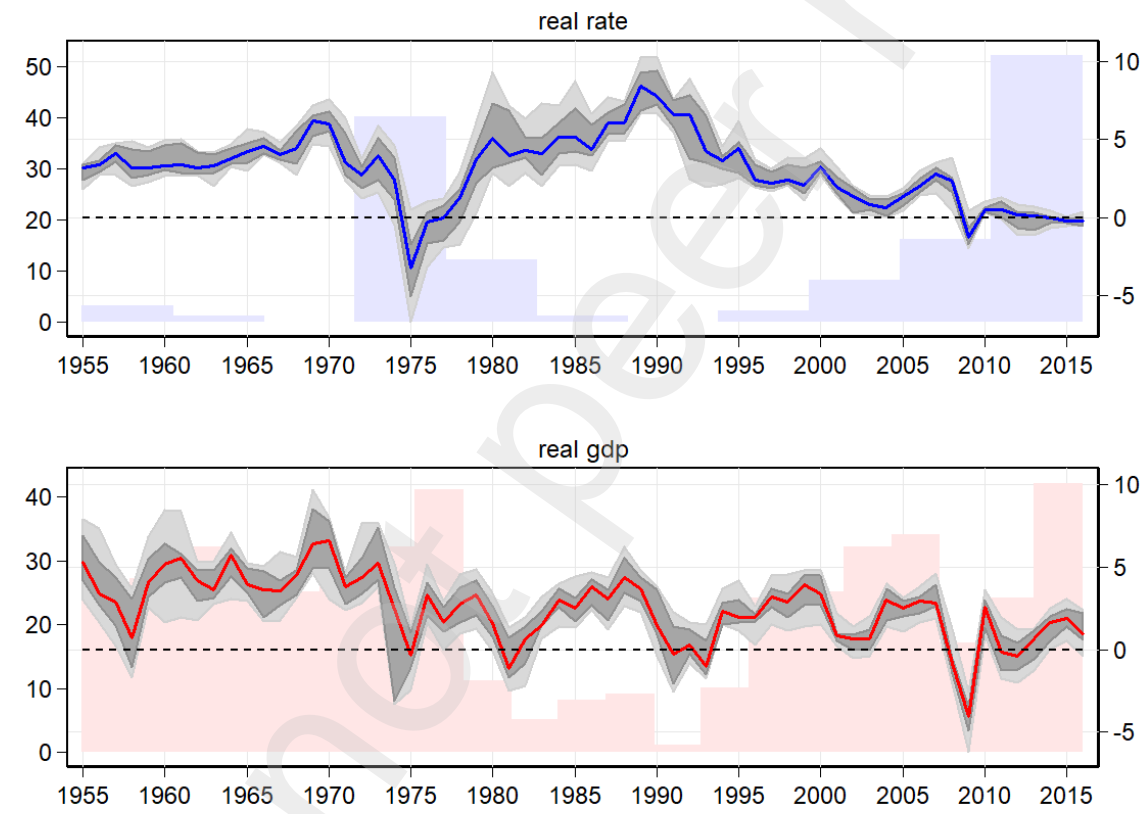

Figure 2: Cross-country medians of real interest rate (top panel, right axis) and annual growth of real GDP (bottom panel, right axis). The bands show different percentile intervals, 35th-65th (30\%) and 20th-80th $(60 \%)$. The background shadow areas represent the frequencies of NIR (top panel, left axis) and LIR (bottom panel, left axis) in sample countries for groups of years.

Figure 2 reports the cross-country median of the real interest rate (blue line), the real GDP

\footnotetext{
${ }^{23}$ We carry out the analysis with expected inflation estimated over 15 and 20 -years windows too. Results are not dissimilar to the benchmark estimation and are available upon request.

${ }^{24}$ Notice that the definition of dynamic inefficiency in Abel et al. (1989) relies on the return on capital, which is the sum of the risk-free real rate and the risk premium. Hence, even if the risk-free interest rate is lower than the economy's growth rate, the return on capital can be higher because of the risk premium. A recent discussion on this issue can be found in Blanchard 2019).
} 
growth rate (red line), and two percentile intervals in the grey areas - 35th-65th (30\%) and 20th-80th $(60 \%)$ - showing the dispersion of the time-series among countries (right axis). The graph starts in the post-World War II period. During the decade 1960-1970, the countries' real rates were steady and the economic growth sustained, until the simultaneous drop corresponding to the Great Inflation period of the mid-1970s. Then, the real rate climbed up until the early1990s, while the economic growth was fairly sound and not volatile in the grace period of Great Moderation between the mid-1990s and the early-2000s. Finally, the real rate slowed down gradually up to today, and the growth rate recovered slowly but consistently from the trough of the Great Recession. The background areas of the figures report the frequencies (left axis) of LIR (red bins) and NIR (blue bins) periods in the countries of the sample for a group of years. Overall, LIR periods occur in $45 \%$ of the observations, while NIR in $13 \%$ of them. Both conditions hold mainly in the years of the Great Inflation and the Great Recession. The frequency of NIR increases progressively starting from 1995 up to the end of the sample, reaching the highest concentration in the post-Great Recession era (more than 50\% observations between 2011 and 2016). This makes our sample a bit inconvenient for showing that "NIR sow the seed of the next bubble" empirically. Nevertheless, the results we present next are not dissonant with this argument.

\subsection{Bubbles identification: leveraged and unleveraged}

We employ a two-steps strategy to catch bubbly events in our sample. First, we identify generic bubbles by looking at both real (CPI-deflated) equity and house prices. We index equity and house prices by taking 1990 as the reference year ${ }^{25}$ Second, to distinguish leveraged from unleveraged bubbles, we look at the overhangs of total loans to non-financial private sector relative to the country's GDP.

We identify the buildup of an asset price bubble and a credit-to-GDP overhang by qualifying an excessive increase in the cyclical component as a deviation from its rolling-window standard deviation. Therefore, we consider a bubble any displacement from the long-run trend higher than the cyclical-standard deviation. This procedure reflects the theoretical intuition of the bubble as price deviations from the fundamental value of an asset.

We employ the Hamilton filter (Hamilton, 2018), to get the cyclical components of credit-toGDP, real equity prices, and real house prices. This filter regresses an actual observation on its past observations for a given time horizon, so that the cyclical component is just the residual of the regression. In this way, the long-run trend is conceived as what can be explained using historical data ${ }^{26}$ We project a horizon of 20 years, which is consistent with the long duration of financial cycles (Hamilton, 2018, Drehmann and Yetman, 2018), by estimating the following

\footnotetext{
${ }^{25}$ Equity prices are the total return on all stocks listed on the country's stock exchange and market cap-weighted. ${ }^{26}$ Drehmann and Yetman 2018 find that the de-trended credit-to-GDP ratio obtained through one-sided Hodrick-Prescott (HP) filter, with a higher smoothing parameter $\lambda$, outperforms many other measures of credit gap in predicting financial crises. The identification through the one-side HP filter delivers similar bubbly events to the Hamilton filter in our case, and the results are available upon request.
} 
equation through OLS:

$$
y_{t+h}=\beta_{0}+\beta_{1} y_{t}+\beta_{2} y_{t-1}+\beta_{3} y_{t-2}+\ldots+\beta_{19} y_{t-20}+\epsilon_{t+h} .
$$

The buildup of an asset price boom is identified whenever the cyclical component, $\epsilon_{t}$, passes from being $\epsilon_{t} \leq \sigma\left(\epsilon_{t}\right)$ to $\epsilon_{t}>\sigma\left(\epsilon_{t}\right)$, where $\sigma\left(\epsilon_{t}\right)$ is the 20-years-window standard deviation of the cyclical component. This condition also identifies the credit overhang periods.

We ultimately identify an asset price bubble only when a boom is followed by a price burst. As in Jordà et al. (2015b), the burst is defined as a decline in the cyclical asset price of at least $15 \%$ (a change of $0.15 \mathrm{log}$-points) within the three years from any point in which the boom condition holds. This further requirement completes our empirical definition of the bubble because it rules out all those price expansions that are rational adjustments to changes in fundamentals. Finally, a leveraged bubble is identified wherever the bubble condition holds together with a credit-toGDP overhang at any point in the time of the bubble event. When a bubble occurs during a period in which credit-to-GDP follows its long-run trend, we identify it as an unleveraged bubble.

Table 6 in Appendix B reports the starting date of the two types of bubbles identified with our strategy. Overall, we find 92 events, 44 leveraged and 48 unleveraged. We capture some of the most famous bubbles of the recent countries' history, such as, for instance, the asset (both stock and house) price bubbles in Japan (peaking in 1990), the dot-com bubble in the US (peaking in 2000), the housing bubble in the US (peaking in 2005), the equity price bubble in Germany (peaking in 2007), and the property bubble in Spain (peaking in 2005). Notice that approximately $80 \%$ of the unleveraged bubbles identified arises from the equity market, while approximately $60 \%$ of leveraged bubbles arise in the housing market. We further explore these different types of bubbles through robustness checks in the next subsections.

\subsection{The logit model and estimation results}

We estimate the probability of observing a leveraged vs an unleveraged bubbly episode, to investigate how low real interest rates and its interaction with the economic growth rate distinguish the two events. We define the benchmark dependent variable as a binary variable that equals one the year before a leveraged bubble starts and zero when an unleveraged bubble starts, $B_{i, t}^{L} \in[0,1]$. Therefore, we take only 92 observations corresponding to the period before the bubbles start. Specifically, we estimate a logistic model as in the following equation:

$$
P\left(B_{i, t}^{L}=1 \mid \alpha_{i}, x_{i, t}\right)=\frac{\exp \left\{\alpha_{i}+\beta\left(x_{i, t}\right)\right\}}{1+\exp \left\{\alpha_{i}+\beta\left(x_{i, t}\right)\right\}},
$$

where $\alpha_{i}$ denotes country fixed effects and $x_{i, t}$ is a vector containing macro predictors. The panel spans the 1947-2016 period for $i=1, \ldots, 17$ countries. The estimation does not include 
time dummies that would account for heterogeneity in bubbles probability over time ${ }^{27}$ However, since similar bubbles affected many countries in the sample, we include robust standard errors clustered at the annual level to account for potential correlation in the error terms and conduct further robustness checks on this point in the next section. To measure the model's classification ability, we report the area under the receiver operating characteristics curve (AUROC) for each specification. The ROC measures the optimal balance between the true positive and the false positive rates, and thus the AUROC is the probability that a randomly chosen realization $B_{i, t}^{L}=1$ is ranked higher than a randomly chosen $B_{i, t}^{L}=0{ }^{28}$

The estimated coefficients are expressed in the form of log-odds ratios, and their economic meaning is central to our empirical analysis. For our dependent variable, an estimated coefficient reveals the log-odd of having a leveraged bubble relative to having an unleveraged bubble, given a marginal change of the predictor. A negative value of the log-odds ratio means that the odds ratio is smaller than one, that is the probability of having a leveraged bubble is lower than the probability of an unleveraged bubble ${ }^{29}$ In our case, a negative log-odds ratio to the real interest rate indicates that a marginal decrease (increase) in the real rate increases (decreases) the probability that a coming bubble will be leveraged rather than unleveraged. Since we include interaction terms in the estimation, we also compute the marginal effect of a change in the real rate conditioning on being in a reported state to provide the reader with a numerical interpretation of the results.

Models 1 to 4 reported in Table 1 focus on the role that the real interest rate plays in predicting the type of coming bubble. Model 1 includes country fixed effects and the real interest rate $r$. Model 2 includes fixed effects, the real rate, and its interaction with a dummy accounting for LIR periods. The (negative) log-odds ratio in the second row signals that a marginal reduction of $r$ during LIR significantly increases the probability the next bubble will be leveraged. Model 3 considers the case of a negative interest rate explicitly, adding to Model 2 a dummy accounting for NIR periods. The log-odds ratio of the interaction between NIR and $r$ is still negative but non significant. However, note that only seven observations are concomitant with NIR periods ${ }^{30}$

We check the stability of log-odds ratios in Model 4 by including six macro controls such as the inflation rate, and the growth rates of real GDP (in per-capita terms), real total loans, real money (M1), real stock and house prices. This implies a fair reduction in the bubbly episodes up to 83 observations. The sign of the real rate in the first row turns significant, while the other signs are preserved, and the predictive ability of the model improves, with the AUROC reaching

\footnotetext{
${ }^{27}$ Although time dummies would improve the ex-post fit of the model by catching the global time factors that drive the left-hand-side of the logit, they are unknown ex-ante. Hence, they are of little help for the out-of-sample forecasting (Schularick and Taylor 2012).

${ }^{28} \mathrm{An}$ AUROC of 0.5 indicates that the ability of the model in classifying realizations is like flipping a coin, whereas a value of 1 indicates a perfect classifier.

${ }^{29}$ Assume $P$ is the probability of having a leveraged bubble. If $P\left(B_{i, t}^{L}=1\right)=\ln \left(\frac{P}{1-P}\right)<0$, exponentiating the latter yields $O D D S=\frac{P}{1-P}<1$.

${ }^{30}$ We have excluded those bubbles emerging when $r>g$ and $r<0$ : one is in 1999 in Japan, when, in the middle of the recession following the 1991's bubble crash, the NIKKEI climbed. The second one is in 1974 in Switzerland, during the recession due to the energy crisis.
} 
Table 1: Logistic model.

\begin{tabular}{|c|c|c|c|c|c|c|c|}
\hline & $\begin{array}{c}\mathrm{r} \\
(1)\end{array}$ & $\begin{array}{l}\mathrm{LIR} \\
(2)\end{array}$ & $\begin{array}{c}\text { NIR } \\
(3)\end{array}$ & $\begin{array}{c}\text { Controls } \\
\text { (4) }\end{array}$ & $\begin{array}{c}(\mathrm{r}-\mathrm{g}) \\
(5)\end{array}$ & $\begin{array}{c}\text { NIR } \\
(6)\end{array}$ & $\begin{array}{c}\text { Controls } \\
\text { (7) }\end{array}$ \\
\hline Real Rate & $\begin{array}{l}-0.11 \\
(0.09)\end{array}$ & $\begin{array}{l}-0.10 \\
(0.09)\end{array}$ & $\begin{array}{l}-0.09 \\
(0.10)\end{array}$ & $\begin{array}{c}-0.32^{* *} \\
(0.15)\end{array}$ & $\begin{array}{l}-0.06 \\
(0.06)\end{array}$ & $\begin{array}{c}-0.02 \\
(0.05)\end{array}$ & $\begin{array}{l}-0.04 \\
(0.06)\end{array}$ \\
\hline Real Rate $\times$ LIR & & $\begin{array}{c}-0.37^{* * *} \\
(0.12)\end{array}$ & $\begin{array}{c}-0.33^{* *} \\
(0.16)\end{array}$ & $\begin{array}{c}-0.71^{* * *} \\
(0.27)\end{array}$ & & & \\
\hline Real Rate $\times$ NIR & & & $\begin{array}{l}-0.94 \\
(0.81)\end{array}$ & $\begin{array}{l}-0.15 \\
(0.69)\end{array}$ & & $\begin{array}{c}-0.58^{*} \\
(0.30)\end{array}$ & $\begin{array}{c}-0.54^{*} \\
(0.32)\end{array}$ \\
\hline Real GDP & & & & $\begin{array}{c}0.01 \\
(0.14)\end{array}$ & & & \\
\hline Inflation Rate & & & & $\begin{array}{c}0.11 \\
(0.11)\end{array}$ & & & $\begin{array}{c}0.03 \\
(0.09)\end{array}$ \\
\hline Total Loans & & & & $\begin{array}{c}0.08 \\
(0.08)\end{array}$ & & & $\begin{array}{c}0.03 \\
(0.07)\end{array}$ \\
\hline Money (M1) & & & & $\begin{array}{c}0.12 \\
(0.10)\end{array}$ & & & $\begin{array}{c}0.05 \\
(0.07)\end{array}$ \\
\hline Stock Price & & & & $\begin{array}{c}0.01 \\
(0.02)\end{array}$ & & & $\begin{array}{c}0.02 \\
(0.02)\end{array}$ \\
\hline House Price & & & & $\begin{array}{c}0.09 \\
(0.06)\end{array}$ & & & $\begin{array}{c}0.03 \\
(0.06)\end{array}$ \\
\hline Pseudo R-squared & 0.11 & 0.15 & 0.15 & 0.25 & 0.11 & 0.13 & 0.18 \\
\hline AUROC & 0.73 & 0.75 & 0.75 & 0.83 & 0.72 & 0.73 & 0.78 \\
\hline Observations & 92 & 92 & 92 & 83 & 92 & 92 & 83 \\
\hline
\end{tabular}

Note: Robust standard errors are clustered at annual level, country fixed-effects and constant terms are not reported. Apart from the real rate, all the variables are in annual growth rates. ( $\dagger$ ) Models 5-7 include the real rate minus the GDP growth rate, $(r-g)$, in place of the real rate.

0.83. Model 4 corrects a potential omitted-variable bias, namely the true effect on the estimated probability being mitigated by some relationship between the real interest rate and some macro variables. However, almost none of the latter is a significant predictor.

Model 4 suggests that the effect of the real rate on the estimated probability reaches the highest magnitude in LIR periods. This could hide the effect during NIR periods, which are a small sub-set of the LIR. We try to address this issue by replacing $r$ with $(r-g)$ in Models from 5 to 7 . By focusing on $(r-g)$, we can exclude the interaction with the LIR, and focus on the interaction with NIR. The specifications without and with controls, Model 6 and 7, show that the log-odds ratio of $(r-g)$ is negative and non significant. However, the interaction terms with NIR have higher log-odds ratios with respect to Model 4, which are now also slightly significant (10\% level).

Given the nonlinear form of equation (16) and the presence of interaction terms in the estimations, we retrieve the average marginal effects (AMEs) of $r$ in Model 4 (Baseline 1) and $(r-g)$ in Model 7 (Baseline 2) to provide our results with a numerical interpretation. Table 2 
Table 2: Average marginal effect from baseline models.

\begin{tabular}{lcccc}
\hline & \multicolumn{2}{c}{ Baseline 1 } & \multicolumn{2}{c}{ Baseline 2 } \\
\hline & $\mathrm{r}>\mathrm{g}$ & $\mathrm{LIR}$ & $\mathrm{r}>0$ & $\mathrm{NIR}$ \\
\hline AME & $-0.06^{* * *}$ & $-0.16^{* * *}$ & -0.00 & $-0.06^{*}$ \\
Standard errors & $(0.008)$ & $(0.03)$ & $(0.01)$ & $(-0.026)$ \\
Z statistics & -6.64 & -3.30 & -0.29 & -2.20 \\
\hline Observations & 83 & 83 & 83 & 83 \\
\hline
\end{tabular}

Note: In Model 4 the AME refers to a marginal change of $r$, while in Model 7 to a marginal change of $(r-g)$. The AMEs are evaluated for sub-periods accourding to LIR and NIR states.

reports the AMEs evaluated for the sub-periods $r>g$ and LIR of Baseline 1, and $r>0$ and NIR of Baseline 2. Standard errors are obtained through the delta method. When $r>g$, a one percent reduction of the real interest rate implies a $6 \%$ increase in the probability that the next bubble will be leveraged rather than unleveraged, while during LIR periods the same probability increase is about $16 \%$. On the other hand, the AME estimated in Model 7 reveals that a one percent reduction of $(r-g)$ increases the probability of the next bubble being leveraged by $6 \%$ in the NIR state. However, the last result has a $10 \%$ significance level.

\subsection{Robustness checks}

We corroborate our findings with robustness checks on the our baseline specifications. In Table 3 we propose several exercises. First, we consider a sub-sample in which bubbles emerging during the years of the oil crises, from 1970 to 1980, are drop out. The extraordinary high inflationary expectations in those years deliver simultaneous periods of low, often negative, real interest rates for several countries that could affect our estimations. The exclusion of those observations reduces bubbly events concomitant with NIR to only four events (two leveraged and two unleveraged bubbles). Therefore, we carry out our Baseline 1 in which we exclude the NIR dummy. Model 8 shows that the log-odds ratios are still negative and significant for both the real rate and its interaction with LIR periods in the smaller sample. Although the sample drops to 69 events, the magnitude of the implied log-odds ratios is higher. Interestingly, the logodds ratios of both inflation and total loans (not reported in the table) turn slightly significant. Overall, this confirms that the results are sensitive to the sample selection and, therefore, we report the comparison between the full and sub-sample in the following exercises.

In Models 9 to 12, we use other nominal rates to estimate the real interest rate. Specifically, we obtain a long-term real rate, which is computed from the nominal yield on a 10-years government bond, and a bond real rate, which is derived from the total nominal return on a representative basket of long-term government bonds. As explained in Jordà et al. (2019), the real bond rates have been as volatile as the real risky returns overtime. Of course, with these two nominal rates 
being usually higher than zero, we cannot account for NIR periods. With respect to the Baseline 1, we find robust results for the bond rate (Model 11 and 12), but not for the long-term rate (Model 9 and 10). In particular, the former presents the highest (negative) log-odds ratio for the interaction term with LIR periods.

\begin{tabular}{lccccc}
\hline & Baseline 1 & \multicolumn{2}{c}{ Long-Term } & \multicolumn{2}{c}{ Bond Yield } \\
\hline & $\mathbf{( 8 )}$ & $\mathbf{( 9 )}$ & $\mathbf{( 1 0 )}$ & $\mathbf{( 1 1 )}$ & $\mathbf{( 1 2 )}$ \\
\hline No 1970s & Full sample & No 1970s & Full sample & No 1970s \\
\hline Real Rate & $-0.73^{* * *}$ & -0.25 & $-0.44^{* *}$ & $-0.64^{* *}$ & $-0.67^{*}$ \\
Real Rate $\times$ LIR & $(0.27)$ & $(0.20)$ & $(0.19)$ & $(0.27)$ & $(0.40)$ \\
& $-1.28^{* * *}$ & -0.40 & -0.27 & $-2.92^{*}$ & $-6.51^{* * *}$ \\
& $(0.44)$ & $(0.37)$ & $(0.51)$ & $(1.62)$ & $(1.74)$ \\
\hline Pseudo R-squared & 0.30 & 0.23 & 0.22 & 0.32 & 0.38 \\
AUROC & 0.78 & 0.81 & 0.77 & 0.86 & 0.81 \\
\hline Observations & 69 & 83 & 74 & 75 & 67 \\
\hline
\end{tabular}

Table 3: Robustness checks. Different specifications for the Baseline 1. Robust standard errors are clustered at annual level, country fixed-effects, dummies, controls and constant terms are not reported.

Lastly, in Table 4 we estimate the Baseline 1 (Models 13 and 14) and the Baseline 2 (Models 15 and 16) by using a different dependent variable that equals one for housing-price bubbles and zero for stock-price bubbles. We have already pointed out that the most of our unleveraged bubbles emerges from the stock market, while a remarkable fraction of leveraged bubbles emerges from the housing market. This is consistent with our theoretical analysis and, especially, with that in Bengui and Phan (2018). A precondition for a leveraged bubble to emerge is a sufficiently high $\phi$. As houses can be more easily collateralized than stocks, the corresponding $\phi$, say, a loanto-value ratio, is higher. Hence, the condition for the existence of a leveraged bubble is in general more easily met if the bubble is attached to house rather than to stock prices. Remarkably, all the specifications in Table 4 present positive and strongly significant log-odds ratios for real loans growth (not reported in the table).

The above theoretical implication meets our empirical results when the Baseline 1 is estimated on the sub-sample without the oil crises' period. In this case, the short-term real rate is helpful in distinguishing the housing from the stock price bubbles. Moreover, housing price bubbles are more likely when the real rate reduces during LIR periods, confirming our main result. Yet, this last exercise confirms that the overall results are less solid regarding the Baseline 2: the fact that bubbles during NIR periods are infrequent makes most of the estimates of the log-odds ratio unstable and non-significant. Nevertheless, the stability of the results related to LIR periods encourages to consider this logistic "early warning" framework as a promising tool to explore the relationship between NIR and bubbly episodes in the near future. 


\begin{tabular}{lcccc}
\hline & \multicolumn{2}{c}{ Baseline 1 } & \multicolumn{2}{c}{ Baseline 2 } \\
\hline & $\mathbf{( 1 3 )}$ & $\mathbf{( 1 4 )}$ & $\mathbf{( 1 5 )}$ & $\mathbf{( 1 6 )}$ \\
\hline Full sample & No 1970s & Full sample & No 1970s \\
\hline Real Rate & $-0.19^{*}$ & $-0.40^{* * *}$ & 0.06 & 0.10 \\
& $(0.11)$ & $(0.15)$ & $(0.10)$ & $(0.11)$ \\
Real Rate $\times$ LIR & -0.50 & $-0.95^{* *}$ & & \\
& $(0.31)$ & $(0.44)$ & & \\
Real Rate $\times$ NIR & -0.38 & -3.49 & -0.01 & 1.08 \\
& $(0.84)$ & $(2.36)$ & $(0.16)$ & $(1.46)$ \\
\hline Pseudo R-squared & 0.36 & 0.42 & 0.24 & 0.23 \\
AUROC & 0.87 & 0.89 & 0.81 & 0.73 \\
\hline Observations & 83 & 72 & 83 & 72 \\
\hline
\end{tabular}

Table 4: Robustness checks. Different dependent variable (housing vs asset price-driven bubbles). Robust standard errors are clustered at annual level, country fixed-effects, dummies, controls and constant terms are not reported.

\section{Conclusions}

Leveraged asset price bubbles are accompanied by credit booms that can painfully hurt the economy in the bust phase, triggering financial crises and deep recessions. In contrast, unleveraged bubbles are less likely to turn into a financial crisis or to cause a severe recession when they burst. As not all bubbles are alike in terms of financial and macroeconomic instability, not all bubbles are likely with low risk-free interest rates.

Low risk-free interest rates affect the probability of a leveraged vs an unleveraged bubble, as shown by our empirical analysis of past bubbly episodes in advanced economies. To discern the bubble's nature, the relationship between the real returns on safe assets and the growth rate of the economy plays a pivotal role. Our logistic estimations show that the lower the real interest rate, the higher the probability of observing a leveraged bubble rather than an unleveraged one. We find evidence that this probability is even higher when the risk-free real rate lies below the economy's growth rate. With negative rates rarely being concomitant with bubbly episodes in our historical dataset, we find weak evidence of that probability magnified in the negative real rates environment. However, as these episodes are concentrated in the most recent part of the sample, and with negative rates being the most plausible scenario of the coming years, we look at those low significance levels as a promising reminder for future research.

Our OLG model provides a theoretical explanation for these empirical findings based on risk-shifting. When an economy's growth rate is higher than the risk-free real interest rate, it is a sufficient condition for leveraged bubbles to emerge but not for unleveraged bubbles. Investors/borrowers shift the bubble bursting risk to lenders by collateralizing the bubbly investment, and thus a relatively low rate of return on bubbly assets makes leveraged bubbles profitable. Therefore, a low real interest rate, especially if negative, discourages investment in 
risk-free assets and encourages leveraged investment in bubbly assets. This is not necessarily the case for an unleveraged bubbly investment, which could be less profitable for investors/lenders than risk-free assets because of the bubble bursting risk, even if the real interest rate is negative.

Given the prospect of persistently low interest rates, and in particular of a negative real rate, in the post-Covid-19 pandemic recovery period, our results have relevant policy implications. In the face of the Covid-19 pandemic, most of the central banks in advanced economies have cut the policy rate to zero and implemented unconventional monetary policies in the form of massive asset purchases, which have pushed interest rates further down. Although these policy measures are essential to sustain the recovery by boosting asset valuations (Caballero and Simsek, $2020 \mathrm{a}$ b), the other side of the coin is their financial instability risk. While it is well-known that asset bubbles are generally more likely in a low interest rates environment, our analysis adds the key element that the most detrimental asset bubble is also the likeliest in such an environment.

This salient aspect, on the one hand, could affect the duration and size of optimal monetary policy measures, which would balance their expansionary impact with the risk and potential cost of emerging leveraged bubbles. On the other hand, our finding seems to ask for closer coordination between monetary and macroprudential policy. Indeed, a precondition for a leveraged bubble is that bubbly assets can be extensively collateralized, as expressed by $\phi=1$ in our OLG model ${ }^{31} \mathrm{~A}$ well-designed macroprudential policy could prevent the excessive collateralization of the assets, allowing the monetary authority to pursue expansionary policies without the risk of fostering leveraged bubbly episodes.

Both policy implications, in any case, deserve further investigation, and a consequent extension of our theoretical and empirical strategy. On the theoretical front, to study the optimal monetary and macroprudential policy, the monetary authority would also implement unconventional policies, taking into account the risk of asset bubbles in its objective function. Furthermore, we would introduce a macroprudential authority setting optimally the parameter $\phi$. On the empirical side, we would explore whether restrictive macroprudential policies reduce the impact of the LIR and NIR conditions on the probability of observing a leveraged rather than unleveraged bubble.

\footnotetext{
$\sqrt[31]{\text { Bengui and Phan }} \sqrt{2018}$ in a complementary paper have already emphasized this point.
} 


\section{References}

A. B. Abel, N. G. M. Mankiw, L. H. Summers, and R. J. Zeckhauser. Assessing Dynamic Efficiency: Theory and Evidence. The Review of Economic Studies, January(1):1-19, 1989.

L. Alessi and C. Detken. Identifying excessive credit growth and leverage. Journal of Financial Stability, 35:215-225, 2018.

F. Allen and D. Gale. Bubbles and crises. The Economic Journal, 110(460):236-255, 2000.

J. Andrés, J. D. López-Salido, and E. Nelson. Money and the natural rate of interest: Structural estimates for the united states and the euro area. Journal of Economic Dynamics and Control, $33(3): 758-776,2009$.

G. Ascari and J. Bonchi. (Dis)Solving the Zero Lower Bound Equilibrium through Income Policy. (10/19), Oct. 2019.

V. Asriyan, L. Fornaro, A. Martin, and J. Ventura. Monetary Policy for a Bubbly World. CEPR Discussion Papers 13803, C.E.P.R. Discussion Papers, June 2019.

R. Baldwin and C. Teulings. Secular stagnation: facts, causes and cures. London: Centre for Economic Policy Research-CEPR, 2014.

J. Bengui and T. Phan. Asset pledgeability and endogenously leveraged bubbles. Journal of Economic Theory, 177:280-314, 2018.

B. Bernanke and M. Gertler. Agency Costs, Net Worth, and Business Fluctuations. American Economic Review, 79(1):14-31, March 1989.

O. J. Blanchard. Public debt and low interest rates. American Economic Review, 109(4):11971229, 2019.

C. Borio, P. Disyatat, M. Juselius, and P. Rungcharoenkitkul. Why so low for so long? a long-term view of real interest rates. BIS working paper, 2017.

L. Brainard. Bringing the Statement on Longer-Run Goals and Monetary Policy Strategy into Alignment with Longer-Run Changes in the Economy: a speech at "How the Fed Will Respond to the COVID-19 Recession in an Era of Low Rates and Low Inflation", an event hosted by the Hutchins Center on Fiscal and Monetary Policy at the Brookings Institution. Speech 88680, Board of Governors of the Federal Reserve System (U.S.), Sept. 2020.

R. J. Caballero and A. Simsek. Asset Prices and Aggregate Demand in a "Covid-19"; Shock: A Model of Endogenous Risk Intolerance and LSAPs. NBER Working Papers 27044, National Bureau of Economic Research, Inc, Apr. 2020a.

R. J. Caballero and A. Simsek. Monetary Policy and Asset Price Overshooting: A Rationale for the Wall/Main Street Disconnect. NBER Working Papers 27712, National Bureau of Economic Research, Inc, Aug. 2020b.

G. A. Calvo. Staggered Prices in a Utility-Maximizing Framework. Journal of Monetary Economics, 12(3):383-398, September 1983.

G. Dell'Ariccia, L. Laeven, and R. Marquez. Real interest rates, leverage, and bank risk-taking. Journal of Economic Theory, 149:65-99, 2014. 
M. Drehmann and J. Yetman. Why you should use the hodrick-prescott filter-at least to generate credit gaps. 2018.

G. B. Eggertsson, N. R. Mehrotra, and J. A. Robbins. A model of secular stagnation: Theory and quantitative evaluation. American Economic Journal: Macroeconomics, 11(1):1-48, 2019.

J. Galì. Monetary policy and rational asset price bubbles. American Economic Review, 104(3): $721-52,2014$.

R. J. Gordon. Secular stagnation: A supply-side view. American Economic Review, 105(5): $54-59,2015$.

J. D. Hamilton. Why you should never use the hodrick-prescott filter. Review of Economics and Statistics, 100(5):831-843, 2018.

J. D. Hamilton, E. S. Harris, J. Hatzius, and K. D. West. The equilibrium real funds rate: Past, present, and future. IMF Economic Review, 64(4):660-707, 2016.

K. Holston, T. Laubach, and J. C. Williams. Measuring the natural rate of interest: International trends and determinants. Journal of International Economics, 108:S59-S75, 2017.

D. Ikeda and T. Phan. Toxic asset bubbles. Economic Theory, 61(2):241-271, 2016.

Ò. Jordà, M. Schularick, and A. M. Taylor. When credit bites back. Journal of Money, Credit and Banking, 45(s2):3-28, 2013.

Ò. Jordà, M. Schularick, and A. M. Taylor. Betting the house. Journal of International Economics, 96:S2-S18, 2015a.

Ò. Jordà, M. Schularick, and A. M. Taylor. Leveraged bubbles. Journal of Monetary Economics, 76:S1-S20, 2015b.

Ò. Jordà, K. Knoll, D. Kuvshinov, M. Schularick, and A. M. Taylor. The rate of return on everything, 1870-2015. The Quarterly Journal of Economics, 134(3):1225-1298, 2019.

O. Jordà, S. R. Singh, and A. M. Taylor. Longer-run economic consequences of pandemics. Technical report, National Bureau of Economic Research, 2020.

T. Laubach and J. C. Williams. Measuring the natural rate of interest. Review of Economics and Statistics, 85(4):1063-1070, 2003.

T. Laubach and J. C. Williams. Measuring the natural rate of interest redux. Business Economics, 51(2):57-67, 2016.

K. G. Lunsford and K. D. West. Some evidence on secular drivers of us safe real rates. American Economic Journal: Macroeconomics, 11(4):113-39, 2019.

A. Martin and J. Ventura. Theoretical Notes on Bubbles and the Current Crisis. IMF Economic Review, 59(1):6-40, April 2011.

M. Marx, B. Mojon, and F. R. Velde. Why Have Interest Rates Fallen Far Below the Return on Capital. BIS Working Papers 794, Bank for International Settlements, July 2019.

E. G. Mendoza and M. E. Terrones. An anatomy of credit booms: evidence from macro aggregates and micro data. National Bureau of Economic Research, 2008. 
E. G. Mendoza and M. E. Terrones. An anatomy of credit booms and their demise. Technical report, National Bureau of Economic Research, 2012.

A. Mian, L. Straub, and A. Sufi. Indebted Demand. Technical report, 2020a.

A. Mian, L. Straub, and A. Sufi. The Saving Glut of the Rich and the Rise in Household Debt. Technical report, $2020 \mathrm{~b}$.

J. H. Powell. New Economic Challenges and the Fed's Monetary Policy Review: a speech at "Navigating the Decade Ahead: Implications for Monetary Policy", an economic policy symposium sponsored by the Federal Reserve System. Speech 88646, Board of Governors of the Federal Reserve System (U.S.), Aug. 2020.

L. Rachel and T. Smith. Secular drivers of the global real interest rate. Working Paper no. 571, Bank of England, 2015.

P. A. Samuelson. An exact consumption-loan model of interest with or without the social contrivance of money. Journal of Political Economy, 66(6):467-482, 1958.

S. Schmitt-Grohé and M. Uribe. Downward nominal wage rigidity, currency pegs, and involuntary unemployment. Journal of Political Economy, 124(5):1466-1514, 2016.

M. Schularick and A. M. Taylor. Credit booms gone bust: Monetary policy, leverage cycles, and financial crises, 1870-2008. American Economic Review, 102(2):1029-61, 2012.

L. H. Summers. Us economic prospects: Secular stagnation, hysteresis, and the zero lower bound. Business Economics, 49(2):65-73, 2014.

J. Tirole. Asset bubbles and overlapping generations. Econometrica, pages 1499-1528, 1985.

P. Weil. Confidence and the real value of money in an overlapping generations economy. The Quarterly Journal of Economics, 102(1):1-22, 1987.

\section{Appendix}

\section{A Theoretical model}

\section{A.1 Supply-side}

\section{A.1.1 Distribution of income between profit and wage}

Firms operate for one period and, as there is no capital 32 they employ only the labor input $L_{t}$. The production technology is

$$
Y_{t}=L_{t}^{\alpha},
$$

\footnotetext{
${ }^{32}$ We abstract from capital because the downward trend in risk-free interest rates is not accompanied by a parallel fall in the return on capital (Marx et al. 2019).
} 
where $0<\alpha<1$. Goods and labor markets are perfectly competitive. Hence, firms take the price of goods, $P_{t}$, and labor services, $W_{t}$, as given, and maximize profits $Z_{t}=P_{t} Y_{t}-W_{t} L_{t}$ under the technological constraint, so that labor is remunerated at its marginal productivity:

$$
\frac{W_{t}}{P_{t}}=\alpha L_{t}^{\alpha-1}
$$

The equation above, the labor demand, can be rewritten as

$$
\frac{W_{t}}{P_{t}} L_{t}=\alpha Y_{t}
$$

which expresses the share of aggregate output/income attributed to the labor input. By using 17), we can also compute the share of income accruing to households in the form of real profits:

$$
\frac{Z_{t}}{P_{t}}=(1-\alpha) Y_{t}
$$

\section{A.1.2 Distribution of income between lenders and borrowers and DNWR}

As described in the main text, only young households earn a positive income by running firms and supplying labor. The young generation consists of lenders and borrowers, but their firms are all identical and thus they yield the same profit,

$$
\frac{Z_{t}^{L}}{P_{t}}=\frac{Z_{t}^{B}}{P_{t}}=\frac{Z_{t}}{P_{t}}
$$

regardless of their owner's identity. On the other hand, workers, borrowers and lenders, are unwilling to accept a nominal wage below a minimum level:

$$
W_{t}=\max \left\{\gamma \Pi^{*} W_{t-1}, W_{t}^{\text {flex }}\right\}
$$

where $\gamma \in(0,1)$ and $\Pi^{*}>\gamma \Pi^{*}>1$. The lower bound on the nominal wage, $\gamma \Pi^{*} W_{t-1}$, is a fraction of its past level indexed to the gross inflation target $\Pi^{*}$, while $W_{t}^{\text {flex }} \equiv \alpha P_{t} \bar{L}^{\alpha-1}$ is the "flexible" wage corresponding to full employment.

The aggregate labor demand from firms is the weighted average of the demand for borrowers' and lenders' labor services, which is respectively $L_{t}^{B}$ and $L_{t}^{L}$ :

$$
L_{t}=(1-\chi) L_{t}^{B}+\chi L_{t}^{L} .
$$

All young agents are equally skilled, and they supply labor inelastically so that the aggregate labor supply coincides with the economy's labor endowment, $\bar{L}=(1-\chi) \bar{L}^{B}+\chi \bar{L}^{L}$. However, lenders have a higher labor endowment than borrowers, $\bar{L}^{L}>\bar{L}^{B}$. Furthermore, the demand for the labor services of both ones is a constant share of the aggregate labor demand that equals the 
corresponding share of the total labor endowment:

$$
\begin{gathered}
\chi \frac{L_{t}^{L}}{L_{t}}=\chi \frac{\bar{L}^{L}}{\bar{L}}=1-\varepsilon \\
(1-\chi) \frac{L_{t}^{B}}{L_{t}}=(1-\chi) \frac{\bar{L}^{B}}{\bar{L}}=\varepsilon .
\end{gathered}
$$

These two conditions imply that any fall in the aggregate labor demand relative to the economy's labor endowment causes a proportional decline in the demand for borrowers' and lenders' labor services, without redistributing income among young households. On the other hand, given the total income of lenders

$$
Y_{t}^{L}=\frac{Z_{t}}{P_{t}}+\frac{W_{t}}{P_{t}} L_{t}^{L}=(1-\alpha) Y_{t}+\alpha Y_{t} \frac{L_{t}^{L}}{L_{t}}
$$

and that of borrowers

$$
Y_{t}^{B}=\frac{Z_{t}}{P_{t}}+\frac{W_{t}}{P_{t}} L_{t}^{B}=(1-\alpha) Y_{t}+\alpha Y_{t} \frac{L_{t}^{B}}{L_{t}},
$$

$Y_{t}^{L}>Y_{t}^{B}$ directly follows from 20, 21) and $\bar{L}^{L}>\bar{L}^{B}$. Finally, the aggregate income/output is the weighted average of the lenders' and borrowers' total income:

$$
Y_{t}=(1-\chi) Y_{t}^{B}+\chi Y_{t}^{L}
$$

\section{A.2 Monetary policy}

Monetary policy is specified in terms of a standard Taylor rule subject to ZLB $\left(1+i_{t} \geq 1\right)$ :

$$
1+i_{t}=\max \left(1,\left(1+r^{f}\right) \Pi^{*}\left(\frac{\Pi_{t}}{\Pi^{*}}\right)^{\phi_{\pi}}\right)
$$

where $\phi_{\pi}>1,\left(1+r^{f}\right) \Pi^{*}$ is the target for the gross nominal interest rate and $r^{f}$ is the "natural" rate of interest corresponding to output at the potential level, $Y^{f}=\bar{L}^{\alpha}=\left[(1-\chi) \bar{L}^{B}+\chi \bar{L}^{L}\right]^{\alpha}$. Finally, the standard Fisher equation

$$
1+r_{t}=\left(1+i_{t}\right) E_{t} \Pi_{t+1}^{-1}
$$

holds, where $\Pi_{t}=P_{t} / P_{t-1}$ is the gross inflation rate and $E_{t}$ is the expectation operator.

\section{A.3 Aggregate demand}

When the nominal interest rate is positive, $1+i>1$, we can derive the $\mathrm{AD}$

$$
Y_{A D}=(1-\chi) Y^{B}+(1-\chi)\left(\frac{1+\beta}{\beta}\right)\left(\frac{\Pi^{*}}{\Pi}\right)^{\phi_{\pi}-1} \frac{D}{1+r^{f}}
$$


from the equations (5), 24, 25), and (26). Combining the same equations yields a different AD with a binding ZLB, $1+i=1$ :

$$
Y_{A D}=(1-\chi) Y^{B}+(1-\chi)\left(\frac{1+\beta}{\beta}\right) \Pi D .
$$

\section{A.4 LIR equilibrium}

Before listing all the steady state variables, we can alternatively express equation (28), which defines the demand-determined output level in the LIR equilibrium, as

$$
Y_{A D}^{L I R}=\left[\frac{(1-\chi)}{1-(1-\chi)(1-\alpha)-\varepsilon \alpha}\right]\left(\frac{1+\beta}{\beta}\right) D \Pi
$$

by using equations $(21)$ and $(23)$.

$$
\begin{gathered}
p^{b}=b^{B}=b^{L}=0 \\
\xi=h=0 \\
1+i=1 \\
1+r=\frac{1}{\gamma \Pi^{*}}<1 \\
\Pi=\gamma \Pi^{*} \\
Y=Y_{A D}^{L I R} \\
L=\left(Y_{A D}^{L I R}\right)^{\frac{1}{\alpha}} \\
L^{B}=\frac{\varepsilon}{1-\chi} L \\
L^{L}=\frac{1-\varepsilon}{\chi} L \\
\frac{W}{P}=\alpha L^{\alpha-1} \\
\frac{Z}{P}=(1-\alpha) Y
\end{gathered}
$$




$$
\begin{gathered}
d^{B}=\gamma \Pi^{*} D \\
d^{L}=\left(\frac{1-\chi}{\chi}\right) \gamma \Pi^{*} D \\
C_{y}^{B}=Y_{A D}^{L I R}-\frac{1}{\beta} d^{B}-T \\
C_{o}^{B}=T-D \\
C_{y}^{L}=\frac{1}{\beta} d^{L} \\
C_{o}^{L}=\frac{1-\chi}{\chi} D
\end{gathered}
$$

\section{A.5 Unleveraged bubble: borrowers' bubble holdings}

Given $\phi=0$, the borrowers' constraints become

$$
\begin{gathered}
C_{y}^{B}=Y^{B}+d^{B}-p^{b} b^{B}-T \\
C_{o}^{B}=\left\{\begin{array}{lll}
T-(1+r) d^{B} & \text { bubble } & \text { bursting } \\
T+p^{b} b^{B}-(1+r) d^{B} & \text { bubble } & \text { survival. }
\end{array}\right.
\end{gathered}
$$

The optimality conditions of the borrowers' maximization problem are

$$
\begin{gathered}
\frac{1}{C_{y}^{B}} p^{b} \geq \beta(1-\rho)\left[\frac{1}{T+p^{b} b^{B}-(1+r) d^{B}}\right] p^{b} \\
\lambda_{d}^{B}=\frac{1}{C_{y}^{B}(1+r)}-\beta\left[\rho \frac{1}{T-(1+r) d^{B}}+(1-\rho) \frac{1}{T+p^{b} b^{B}-(1+r) d^{B}}\right]>0 .
\end{gathered}
$$

where $\lambda_{d}^{B}$ is the Lagrange multiplier associated with the credit constraint (1), and it is strictly positive because borrowers are credit constrained by assumption. When borrowers cannot collateralize the bubble, they can only use it as a store of value, and thus they buy it if the marginal cost of the bubble on the left-hand side of $(29)$ is equal to its marginal benefit, given by the discounted expected return on the bubble, on the right-hand side. By contrast, if the marginal cost is higher than the marginal benefit, borrowers do not value the bubble, and their optimal bubble holdings are zero. We assume here that borrowers hold the bubble, so that equation 29 holds with equality. At the same time, also lenders hold the bubble, and their optimality 
conditions are (8) and (9). Combining $(8),(9),(29)$, and $(30)$ yields the following condition:

$$
b^{B}<\frac{T-D}{T(1-\chi)} \text {. }
$$

The condition above does not lead to a contradiction, proving that lenders' and borrowers' optimality conditions are not mutually exclusive, and thus both agents can hold simultaneously bubbly assets. Indeed, this condition imposes only an upper bound on the borrowers' bubble holdings, which reflects their weak incentive to hold bubbly assets when $\phi=0$. The borrowers' demand for bubbles can be meager for a small value of $T$, but, in any case, it can be positive because of $T>D$.

\section{A.6 Leveraged bubble: lenders' bubble holdings}

We aim to prove, by contradiction, that if borrowers hold the bubble, lenders do not. For $\phi=1$, the optimality conditions of lenders are still given by (8) and (9), as stated in the main text. For the sake of convenience, we rewrite these equations here:

$$
\begin{gathered}
\frac{1}{C_{y}^{L}} p^{b}=\beta(1-\rho)\left[\frac{1}{p^{b} b^{L}+(1+r) d^{L}}\right] p^{b} \\
\frac{1}{C_{y}^{L}}=\beta(1+r)\left[\rho \frac{1}{(1+r) d^{L}}+(1-\rho) \frac{1}{p^{b} b^{L}+(1+r) d^{L}}\right] .
\end{gathered}
$$

We assume lenders demand a positive quantity of bubbly assets, and thus the first condition holds with equality. Combining these two equations yields

$$
(1+r)=(1-\rho)-\frac{\rho p^{b} b^{L}}{d^{L}}<1 .
$$

However, if borrowers hold the bubble too, combining their optimality conditions 12 and 13 , yields

$$
(1+r)=1 .
$$

This leads to a contradiction. Therefore, if borrowers hold the bubble, lenders optimally choose not to for $\phi=1$. 


\section{B Data and figures}

\begin{tabular}{lccccc}
\hline Variables & Obs. & Mean & St.Dev & Min & Max \\
\hline Real GDP & 1173 & 2.709 & 3.726 & -15.058 & 29.425 \\
Short-term rate & 1175 & 5.381 & 4.073 & -2 & 21.273 \\
Long-term rate & 1188 & 6.494 & 3.61 & -0.14 & 21.503 \\
Bond rate & 1102 & 0.066 & 0.036 & 0 & 0.215 \\
Baseline real rate & 1115 & 3.469 & 3.479 & -10.303 & 28.456 \\
CPI Inflation & 1173 & 4.354 & 4.768 & -19.355 & 56.49 \\
Inflation Expectations & 1122 & 2.053 & 3.177 & -7.55 & 20.483 \\
Real Loans & 1169 & 4.815 & 6.995 & -19.151 & 76.567 \\
Real Money (M1) & 1140 & 3.361 & 5.754 & -23.42 & 60.018 \\
Stock prices & 1121 & 1.226 & 23.088 & -223.294 & 96.031 \\
Housing prices & 1063 & 1.563 & 7.998 & -38.964 & 71.28 \\
\hline
\end{tabular}

Table 5: Summary of variables in the estimations. Except for the rates of interest, all the variables are expressed in growth rates. Raw data can be retrieved from Jordà et al. (2019).

\begin{tabular}{lcc}
\hline Country & Leveraged (starting year) & Unleveraged (starting year) \\
\hline Australia & $1966 ; 1973 ; 2002$ & 1998 \\
Belgium & $1966 ; 1978 ; 2004 ; 2007$ & $1988 ; 1998 ; 2010$ \\
Canada & $1964 ; 1973 ; 2009$ & $1961 ; 1980 ; 1997 ; 2005 ; 2006$ \\
Denmark & $2005 ; 2010$ & $1960 ; 1971 ; 1996 ; 1999$ \\
Finland & $1987 ; 2005 ; 2009$ & $1964 ; 1965 ; 1997$ \\
France & 2003 & $1964 ; 1983 ; 1987 ; 1997 ; 2000$ \\
Germany & 1987 & $1972 ; 1978 ; 2005 ; 2013$ \\
Italy & $1973 ; 1988 ; 2005$ & $1959 ; 1998$ \\
Japan & $1972 ; 1984 ; 1989$ & $1960 ; 1964 ; 1998 ; 2010$ \\
Netherland & $1976 ; 1998 ; 1999$ & $1961 ; 1982 ; 1988$ \\
Norway & $1960 ; 1985 ; 2004$ & 1998 \\
Portugal & $1970 ; 2001$ & 1961 \\
Spain & 2004 & $1960 ; 1998$ \\
Sweden & $1989 ; 2003 ; 2005$ & $1984 ; 2000 ; 2010$ \\
Switzerland & $1965 ; 1987 ; 1988 ; 2014$ & $1973 ; 2007$ \\
UK & $1985 ; 1987 ; 2003$ & $1973 ; 1999$ \\
USA & $1961 ; 2003$ & $1959 ; 1989 ; 1996$ \\
\hline
\end{tabular}

Table 6: Leveraged and unleveraged bubbles. The table reports the starting date of the events for each country in the sample. Note that if two bubbles occur with a one-year lag it is because they come from different asset-price booms (equity/housing prices). 